\title{
Universiteit
}

Leiden

The Netherlands

\section{Virtualization of dispute resolution. Establishing trust by recycling reputation \\ Mommers, L.}

\section{Citation}

Mommers, L. (2006). Virtualization of dispute resolution. Establishing trust by recycling reputation. Information \& Communications Technology Law , 15(2), 175-188. doi:10.1080/13600830600676602

Version: $\quad$ Not Applicable (or Unknown)

License: $\quad$ Leiden University Non-exclusive license

Downloaded from: $\quad$ https://hdl.handle.net/1887/13084

Note: To cite this publication please use the final published version (if applicable). 


\title{
Virtualization of Dispute Resolution. Establishing Trust by Recycling Reputation
}

\section{LAURENS MOMMERS}

Centre for Law in the Information Society, Leiden, The Netherlands

\begin{abstract}
Virtualization of dispute resolution is triggered partly by the introduction of new information and communication technologies, but primarily by the effective use of those technologies. In this article, we analyze how the introduction of ICTs can affect one major topic in the realm of virtualization phenomena: the shift from dispute resolution to dispute prevention. The technologies for establishing trust in on-line communities involve great opportunities, but also major risks, for the establishment of trust across communities, thereby preventing disputes from occurring. We will sketch a framework suitable for assessing such changes in order to maintain legitimacy in dispute resolution and dispute prevention on the internet.
\end{abstract}

\section{Introduction}

Once we wrote letters, nowadays we write e-mails. Anyone who persists in claiming the functional equivalence of a letter and an e-mail fails to see the many new opportunities delivered by e-mail-in terms of nearly real-time locationindependent communication-and denies the very essence of electronic communication, including the loss of long, well-written and substantial content that letters once had, and that is very rare in e-mail. The value of the transition from letters to e-mails, from typewriters to word-processors, from working behind a desk to working behind a computer, is not only found in the improvement of functions that were already there. Virtualization means that the introduction of new technologies triggers changes in processes and functions, and the creation of new ones. This applies not only to the way in which we write texts, but also to the methods we use to resolve disputes.

In the current article, we will evaluate the meaning of 'virtualization of dispute resolution'. It is not an easy task to analyse virtualization while we find ourselves in the middle of that process. Introduction of computers in courts has only started relatively recently, on-line alternative dispute resolution has also only emerged before the turn of the century, and it is clear to almost everyone that opportunities are not taken to their full potential. Can we do more with information and communication technology (ICT) in dispute resolution than just supporting existing work processes? The answer should be: yes, but one article-or even a special issue-is certainly not enough to sketch all current and foreseeable developments in this area. That is why in this article, there is only one more elaborate discussion of a virtualization process, in addition to a more general explanation of virtualization. To show how 'virtual' it can get, we discuss the 
replacement of dispute resolution by dispute prevention in an on-line context: how the existing types of dispute prevention can be taken even furthercompared to, e.g. eBay's feedback system. And to judge the consequences of such virtualization processes, an evaluation framework is provided, in terms of legitimacy criteria.

Prior to explaining how dispute prevention can be facilitated, we will investigate how ICT influences certain functions that are relevant to dispute resolution. In section 2, the meaning of the phrase 'virtualization of dispute resolution' will be explored. In section 3, we will discuss the functions that are exercised with ICT, and the ways in which these functions will develop with respect to dispute resolution. The selection of so-called functional areas indicates in what manners ICT can be used: for administration, communication, access and assessment. In section 4, we discuss an essential precondition for building and extending virtual communities, namely trust. In section 5, we discuss a scenario for a way in which to turn the need for dispute resolution in cyberspace into dispute prevention. In section 6, we explain how virtualization in dispute resolution can be assessed in normative terms: if dispute resolution changes, what criteria can be used to see if the change is for the better? In section 7 , conclusions are provided.

\section{Virtualization}

'Dispute resolution' means that a conflict between parties is settled by means of consultation, negotiation, mediation, arbitration or litigation. 'Virtualization of dispute resolution' can be clarified by an analogy. Consider the transition from a typewriter to a word processor. One could describe a word processor in terms of the functions of a typewriter. But thus one would miss what are probably the most exciting functions of a word processor: re-arranging and re-using texts, and easy checking and correction of mistakes. One would certainly miss the opportunities offered by a word processor in combination with e-mail: rapid distribution of texts, editing by different persons, merging documents into new ones. But then, a word processor with e-mail functionality is no longer equifunctional to a typewriter. So tools change, and in this process, their functions change as well. This suggests that the concept of meaning developed by Wittgenstein (1953) ${ }^{1}$ - meaning as use, illustrated by the game analogy - is of particular relevance to processes of virtualization.

As the meaning of 'game' is not fixed, changing with the different instances or uses of the term, virtualization cuts the meaning of a concept loose from its original function, although there remains a relationship. ICT is used to an increasing degree in traditional, 'off-line' dispute resolution, for instance to support working processes. Additionally, societal changes, such as the popularity of on-line buying, invoke new types of conflicts on a much larger scale than beforehand, and with it a demand occurs for new types conflict resolution. Basically, while virtualization takes place, the 'rules of the game' change. And while the rules change, new types of dispute resolution can emerge. One of these new types is 'on-line dispute resolution', and its rules are developing as we speak. Many new initiatives are part of it, some of which are very successful, and these may point in the direction virtualization of dispute resolution will take.

Richard Susskind discussed the changes in law practice under the influence of ICT in his books the future of law' $^{\prime 2}$ and 'transforming the law'. ${ }^{3}$ Some of his claims regarding the market for legal services are the looming redundance of the 'middle man' (Susskind, 2000, p. 98): functions that were once obviously unified 
can now be broken up. The obtaining of knowledge about some legal issue can be cut loose from, e.g. its articulation and publication (including its use in legal information systems), functions that used to be united in the person of a lawyer. Susskind claims that the legal profession will change from a one-to-one advisory service to a one-to-many information service, that legal professionals will no longer advise clients directly, but that they will use their time to articulate legal knowledge into legal information systems, and that the presence of those information services empowers the people concerned to contribute to the moulding of the law, so that legal services will become proactive instead or reactive (Susskind, 2000, pp. 101-105).

Susskind also lists a number of foreseeable developments in legal process, two of which are mentioned here. First, the proactive functioning of legal professionals and legal services will reduce the number of conflicts; instead, there will be a growing role for risk management, so that disputes will be avoided. Second, the legal system will transform from a print-based system to an IT-based system, enabling legal information to become much more accessible by arranging it in an effective manner (Susskind, 2000, pp. 105-107). What does this mean in practice? If Susskind is right, the product 'legal service' will evolve from personal consultancy to personalized IT services. He predicted this development in 1996, and he did not expect it to be completed in 2005. However, if we take a-rather subjective-look around regarding IT use in the law (for professionals as well as laymen), not that much has changed at all-at least not in The Netherlands.

Although information services have been improved, those information services are really only usable by legal professionals. There has been no substantial increase in dissemination of legal knowledge to the general public. Although all laws and regulations and some case law are now freely available to the general public, legal information services specifically aimed at citizens and companies are still quite sparse, with a few notable exceptions. A web-site ${ }^{4}$ under the direction of the Dutch ministry of economic affairs provides information on consumers' rights in business-to-consumer relations. It provides information based on the phases before, during and after buying a product. Still, legal information services that effectively map consumers' questions to (legal) solutions are very rare. Consequently, there still seems to be quite a gap between Susskind's prediction and the reality of legal services in 2005 .

Considered from a different viewpoint, however, Susskind's prediction can be deemed correct: many Dutch citizens (and all Dutch companies, as they are obliged to) make their tax declarations electronically. The programmes they use for this purpose incorporate the legal tax rules, explanations of the programmes' functions, and automatically calculate the taxes to be levied. There are two characteristics of such systems that are interesting in the context of virtualized dispute resolution. First, their design is in the hands of the public institution that has an interest in the height of the tax yields. Second, the legislation on which these systems are based is drafted with this specific use in mind, which affects the nature of the legal norms ( $c f$. Lessig, 19995). As to the first characteristic: if a dispute resolution environment is designed by a party which is also involved in actual dispute resolution in that environment, the procedure cannot be deemed independent, and the interests of other parties may be influenced negatively. As to the second characteristic: the opportunities offered by new technologies in dispute resolution environments may in fact impose restrictions on the process of dispute resolution, and thereby annihilate valuable opportunities. 
There is also another area, not as obvious as the ones mentioned above, in which Susskind's predictions prove to be partially correct: the change of the legal profession's character from reactive and problem-solving into pro-active and dispute-preventing. Although the legal profession is not really a party in these systems, there is a shift towards dispute prevention in the area of on-line selling and buying. The eBay community generates a considerable number of (potential) disputes by its mass application of auction and sales transactions between users (mostly private persons and small businesses). eBay has integrated its own conflict resolution system in its service, and the company offers access to SquareTrade services for on-line complaints and mediation as well. These are the dispute resolution systems, to be used when things go wrong. As a means of dispute prevention, eBay has a feedback function, supporting strangers to gain the degree of confidence that they need for doing business. The boundaries between dispute prevention and dispute resolution are fading, as eBay's feedback system shows. Feedback not only functions as an indicator for trust, it is also used to exert pressure and to impose sanctions. Its different roles provide ample support for Katsh' and Rifkin's 'fourth party' metaphor for technology in on-line dispute resolution. ${ }^{6}$ Technology need not (and sometimes cannot) be restricted to make digital clones of traditional dispute resolution functions. Instead, technology offers new functions, new opportunities and new threats.

\section{The view from technology}

Technological development is often a cause for virtualization. In Mommers, ${ }^{7}$ four functional areas of virtualization in information and communication technology are distinguished that are relevant to dispute resolution and other phenomena that are subject to virtualization: administration, communication, access and assessment. In the context of dispute resolution, administration regards, among other things, keeping track of cases and levies. Communication concerns the exchange of information between parties and dispute resolvers. Access regards the way in which parties and dispute resolvers can consult certain information, knowledge and experts. And assessment concerns the views parties develop regarding each other, and the view the dispute resolver develops with respect to the conflict. This distinction serves to apply structure to the many opportunities for virtualization of dispute resolution offered by currently available technologies. Some of the opportunities involve the improvement of existing applications, other ones regard new applications of existing technologies, or even the application of new technologies of which the occurrence can be expected.

Administration is the area in which traditional information technology solutions most often appear: word processing, database administration, financial administration and the like. Administrative IT is a relatively grown-up market, showing standard applications and companies that provide customized solutions. Still, administrative IT suffers from many problems. Two of these problems are the lack of standardization that could facilitate the sharing of information among systems and the lack of tuning of systems to local situations and demands. As a consequence, many systems still function as 'stand alone' entities, not being able to supply or use information from other systems, or to communicate properly with users.

Administrative applications could be further optimized (they could be better equipped for their tasks in dispute resolution), and they could also be connected to each other in order to attain greater efficiency (of course, within preconditions of 
privacy protection and due process). More efficiency in current workflows is only one possibility. Administrative applications can also lead to new processes and workflows. Digital dossiers offer possibilities for performing tasks simultaneously and location-independently. This means that the function of dispute resolution becomes much less bound to specific locations (such as courts). Opportunities offered by administrative virtualization are: (1) efficient (re)use of information, due to not needing to provide the same data more than once-if stored in a proper format; (2) availability of information regardless of place and time, which may make procedures more flexible and collaboration more easy; (3) flexibility of planning: access to people's agendas combined with overviews of the tasks to be performed and dependencies among those tasks can lead to more efficient use of an organization's resources (enterprise resource planning); and (thus) (4) further separation of front office and back office, making the former more client-oriented.

Communication is the area in which traditional communication technologies have earned an important place, featuring regular mail, telephony and fax, recently complemented with new communication forms such as e-mail and instant messaging. New developments in communication technologies (e.g. voice over IP) forced the communication market into turbulence, a situation that can last for years to come. Convergence of communication means (telephony, television and internet through one cable) and new forms of communication (instant messaging) change behaviour patterns. Virtual communication (communication between persons not in each others' physical presence) is now much less bound to location than it was 20 years ago. Twenty years ago, to be able to reach a person by telephone, you had to know where that person was at that particular moment (and, of course, a telephone had to be present as well). This knowledge is no longer required, due to mobile telephony and instant messaging.

Obviously, improved means of communication also imply decreased location dependence in dispute resolution. Synchronous physical communication (which is a difficult way of stating that people talk to each other in person) that traditionally takes place in courts or meeting rooms may be replaced by synchronous virtual communication (video conferences, chat). Asynchronous physical communication (regular mail) can be replaced by asynchronous virtual communication (e-mail, collaborative workspaces). However, these types of virtual communication are still largely analogous to physical communication. It will be interesting to see how new communication technologies will eventually mould procedures related to dispute resolution, due to disappearing constraints and new opportunities. Opportunities of communicative virtualization are: (1) faster, cheaper and more easily accessible means of communication, enabling more regular 'meetings'; (2) communication means other than voice and text (including video, photos, etc.); (3) communication forms 'in between' synchronous and asynchronous communication enable more flexible and efficient interaction (chat, forums); and (4) services supporting those new forms of communication may affect the structure and content of the information exchange, as focus can be brought to particular elements of texts (cf. the use of 'track changes' in Microsoft Word).

Access concerns the way in which persons can consult certain information or use certain services. With respect to access, two opposite effects occur regarding the use of information and communication technology. On the one hand, new communication means lower barriers for obtaining information and access to services. On the other hand, the availability of such communication means may effectively raise the barriers, because there is no-one present who can do the job of 
providing all interested customers with the information they want. So, it might very well happen that a web-site of a certain legal institution does not provide contact details, and not even a feedback form, because it does not know how to handle the responses to be expected. In regard to access, the opportunities offered by information and communication technologies are still wide open. Although the turmoil is less apparent than with communication technology, it is still there, hidden underneath dissatisfied customers and the services they use.

Forms of access change due to virtualization of dispute resolution. This is partly related to changes in communication as they are described in the previous paragraph. Access is used here in a narrower sense: it amounts to the functions of the interface through which information is made available, setting aside the communicative aspects that may be involved. In principle, information present in an organization can be stored in electronic form. Once present in such a form, information can be made available in different ways. Major differences in the access to electronic information compared to paper information are: (1) less need for manual structuring (e.g. in the form of library catalogues); (2) information sources can be searched by their full text; (3) the same information can be made available more easily by different classifications (e.g. for different target groups); (4) there are (limited) possibilities of automatic extraction of, for instance, classification information; and (5) presentation of information can be changed instantly for different target groups and people with various access rights to the information.

Finally, assessment is subject to change under the influence of information and communication technology. This is caused, in part, by the easy way in which, for example, documents can be sent to other people. If a paper has to be assessed by four people in sequence, and this has to be done by regular mail, it will take at least two weeks, whereas by e-mail, the same can be done quite easily within a day (that is, if all people do their jobs immediately). Also, assessment changes under the influence of new techniques for handling the contents of documents. There are many examples of such techniques: mark-up functions in word processors, polls on web-sites, forums that allow users to give feedback to certain statements or questions, on-line questionnaires, simulations of events, etc. The new forms of communication and information processing allow relatively easy processing of such user assessments. The application of these techniques has definitely not reached its full potential yet.

Assessment is the area in which applications in dispute resolution have yet to mature. Although many web services now use assessment systems to improve the quality of their content or their reliability, these developments have largely remained in their original areas of application: the eBay feedback system could be applied in many other areas, but apart from the growing number of applications in e-commerce, effective uses in other areas are not widespread. Other 'reputation management systems' can be found in the area of IT-related internet forums. eBay uses the feedback profile for both users and sellers, which makes sense because most buyers are sellers as well, and vice versa. Reputation management systems in large e-commerce companies focus only on reputation profiles for sellers (e.g. Amazon has a reputation system for so-called 'market place sellers'). Potential forms of virtualization in the area of assessment include: (1) reputation management for individuals, organizations, companies, services and products; (2) interactive feedback forums for articles; (3) wiki-like services for joint text production, or even the drafting of judgements; and (4) simulations that support the assessment of scenario's, for instance in penal cases. 
What will happen with these functional areas if virtualization will continue? One of the main characteristics of virtualization is that little remains the same: as I explained above, a letter is a means of communication, as is an e-mail, but e-mail may perform other functions as well. The ways in which certain activities are performed within the four functional areas mentioned (administration, communication, access and assessment) do not only change on themselves, they also show changing interplay with each other. This is the case because ICT enables automatic links where they were once not possible. Access to administrative data would always require physical presence or a telephone call to a person who would look up your account data for you. That is relatively laborious if you just want to know if some book you ordered will arrive today. Such access nowadays does not necessarily require human involvement, so that many people now use track and trace data to see if they have to stay at home to receive their package. Lower access barriers to such administrative information trigger new types of uses and provide citizens with more opportunities to exercise control over the data kept on them by companies or governments. Developments in the functional areas are hard to predict-but it is even harder to forecast how the developments in different functional areas will affect each other. The scenario described in section 5 shows how such mutual influences may take place. But before discussing that scenario, we have to dig deeper into what it takes to let people do business with each other.

\section{Trust in cyberspace}

In an on-line environment, where you cannot rely on your own senses to assess the reliability of a different person you communicate with or you buy a product or service from, trust is as important an asset as in the off-line world. However, in an on-line environment, it has to be established in a different way. Often, the services of (trusted) third parties are needed in order to underpin the 'claim to fame' of the sender of an e-mail, the owner of a web-site, or the contributor to a forum discussion. In order to know that our browser provides a page of the Amazon website, we have to put trust in our computer's software (including operating system, anti-virus software, anti-spyware software), in our system administrator, the administrators of DNS services, our internet provider, Amazon's system administrator, etc. And last but not least, we have to trust the Amazon brand. If there would be an Amazon megastore in the city centre of our home town, we would not have to go through all this trouble, because we could just pick up a book and pay for it. In a commercial environment, trust is important, because it provides economic value. Experienced buyers will probably pay more for a certain item when they buy it from a trusted seller than when they buy it from a seller unknown to them (if they engage in the latter transaction at all). This is simply a matter of taking into account a risk premium for non-delivery, damaged items or non-compliance.

Many promises were made during the internet's rapid growth in the late 1990s. These promises regarded large-scale accessibility of products and services offered by small companies and individuals, because the distribution network was available to anyone. A few years later, we may conclude that only very few players survived, and the rules of traditional marketing still apply. Amazon and eBay became large players, whose value is largely dependent on their brand names. They have both become large network enterprises, housing many small companies and individuals who take advantage of the value of these companies' brands. The on-line survival of such small companies depends on the presence of 
these large companies, which offer a kind of articulation service. Without the presence of a well-known, trusted company with adequate search facilities, it is relatively difficult to find a small supplier of a product and determine its credibility. It is important to realize that a similar concern is valid for almost any provider of services or goods on the internet.

Essentially, the scenario sketched below is based on the idea that trust provision is vital to dispute prevention and dispute resolution. But is it necessary that such trust provision takes place by concentration of 'trust provision' in commercial enterprises? No, not necessarily. There are companies and organizations that provide trust without their own interfering commercial activities. An example of such an organization is Euro Label, ${ }^{8}$ which does not only provide trust seals, but also offers dispute resolution services. The same is valid for SquareTrade. Additionally, there are many web-sites that give the opportunity to users to assess the quality of on-line shops. Examples are the shop surveys of tweakers.net ${ }^{9}$ and shopping.com. ${ }^{10}$ There are even possibilities of taking out the central entity in quality assessment. Examples of publications on so-called peer-to-peer reputation management are Carey ${ }^{11}$ and Dingledine et al. ${ }^{12}$ These publications describe the possibility of reliable establishment of reputation profiles in non-centralized networks, the so-called peer-to-peer configuration, well known for its use in 'file sharing' applications such as Kazaa.

With the growing number of dispute resolution initiatives, potential users should have some possibility of determining the suitability and quality of a form of dispute resolution. This can be done by a company itself-if it has sufficient credibility itself (Amazon, eBay). Alternatively, it can be done by a third party articulating individual opinions or assessing quality through a certain standard, or the quality may be assessed in a peer-to-peer setting, probably through the articulation of individual opinions. For new initiatives in dispute resolution to be viable, trustestablishing activities are vital. Although the easiest route for such activities is probably through established brands such as eBay, the quality of dispute resolution may very well benefit from a more independent approach. The interests of companies may equal the interests of parties involved in dispute resolution-in which case independence is not that important-but they may diverge as well. eBay profits from large trade volumes and as little negative publicity as possible. These concerns may conflict with customers' interests. The same is valid for dispute prevention. For establishing trust in other 'residents of cyberspace' (people we do some kind of business with through the internet), a system 'owned' by a large business, such as eBay, is probably not the best option. In the next section, we will discuss a method of establishing trust through feedback systems without leaving the contents of such a system to a single institution.

\section{Recycling reputation}

Virtualization implies redesigning and rebuilding existing functions into a new environment. Also, it implies designing and building new functions that fit in with the new environment and take it to its full potential. A more elaborate overview of opportunities and risks of developments (including examples) within the four function groups (administration, communication, access and assessment) can be read in Mommers. ${ }^{13}$ In the remainder of this article, we will focus on the potential merits of combining techniques in those four function groups. The scenario we sketch is far from realized at the moment of writing-and we will ignore all 
potential problems that are attached to it. Combining administration, communication, access and assessment means interfacing different systems and storing loads of information potentially harmful to people's privacy and to the exercise of fundamental rights. That left aside-the corresponding problems would be worth their own study-the opportunities are manifold.

In section 3, we listed potential virtualization phenomena in four functional areas. We claimed that, in the area of administration, there can be efficient (re)use of information and availability of information regardless of place and time; in the area of communication, faster, cheaper and more easily accessible means of communication are available; with respect to access, the same information can be made available more easily by different classifications; and with respect to assessment, reputation management can be built for individuals, organizations, companies, services and products. A mechanism for recycling reputation combines opportunities within these functional areas in order to improve on a reputation management system.

Storing information on, for example, the transactions made by persons and institutions offers others the chance of knowing who they are dealing with. If you regularly visit a shop at the corner of the street where you are living, you probably develop some kind of relation with the shopkeeper. If you forget your wallet one day, the shopkeeper most likely will not hesitate to let you take your cigarettes and newspaper and pay for them next day. This is something you will also come across on the internet, but only within the context of one shop or forum. If you buy something the fifth time from the same internet store, there is a chance that they will allow you to pay afterwards. But there is little chance that your favourite online bookstore will recommend you as a reliable individual to a different store, which would be useful for both consumers and e-businesses.

As much as storing and using personal information is considered a privacy risk, there are major advantages in 'being known' by other people. If you wish to sell your old TV set, the price you will get is higher if the buyer knows that you do not lie about its age or existing defects. If you want a loan, the rate you will get it for will be lower if the bank knows that you always pay back in time. To push it a little further: if you are looking for a relationship, you might benefit from relatively objective information about a person's past. In social network software, this is implemented using the principle: 'a friend of a friend of mine is a friend of mine'. This is most likely not true, but still, the advice of others can contribute to a better grounded opinion. Detaching information from its original use environment could thus, in principle, support many aspects of daily life. We coin the term 'portable reputation profiles' for such detached information. If anyone could reuse reputation information built up in certain contexts, this would enable the kinds of use described below, and undoubtedly, it would support many other uses that have to be invented as yet.

There are two uses of portable reputation profiles that fit in with the scope of this article. The first is for dispute prevention, the second for dispute resolution. If people know more about each other, this will probably lead to a decrease in numbers of certain conflicts, such as disputes arising from buying and selling. If disputes arise after all, background information on both parties may help them to settle the conflict themselves, background information on a dispute resolver may help the parties to select the proper third party, and the dispute resolver may use the profiles of the parties to support the dispute-resolving procedure. This all amounts to the kind of information gathering and use that we know from the 'real world', 
and that supports, in that context, the prevention and resolving of disputes, for the greater part outside the legal system ( $c f$. Ellickson, $1991^{14}$ ). Portable reputation profiles can also be used to assign rights, for instance rights of access to information or rights to assess other people's products or opinions. This type of merit-based rights assignment can help to support the quality of discourse in on-line communities, including discourse supporting dispute prevention and dispute resolution.

What does this scenario amount to in practice, then? Let us assume that $\mathrm{Mr}$ Jones is a regular internet shopper. He buys products at several on-line stores. He also deals at eBay, buying and selling mainly second-hand furniture. Due to his (common) name, he can hardly be traced on the internet (there are almost 200 million hits for 'Jones' in Google), so he has to establish a fixed identity by which he can make himself known to other people and businesses on-line. If he wishes to close a deal at eBay with a person not known to him (let us call him Smith) who has an empty feedback profile, he might want some additional information on that person. Smith can now provide a portable reputation profile (for instance from a different auction site) to Jones, or to eBay, in order to complement his empty eBay feedback profile. On the basis of that feedback profile, Jones can decide to close the deal-or not. Jones, on his turn, can use his eBay feedback profile to get, for instance, better payment conditions at internet shops.

How can such a scenario be realized (again, apart from privacy concerns)? A fixed identity can be established through a trusted third party, which links Jones' name to his personal data with the assurance that he is who he claims to be. Such a personal identity can also be linked to an arbitrary (but unique) nickname, that Jones can use in a context that he wishes to leave traces in, but does not want to be linked to his true identity. For instance, Jones could wish not to reveal to the internet community that he deals in furniture, because he is afraid his house will be visited by thieves or because he is afraid he will lose his job over it. Then again, if Jones wants to start his own internet shop, leaving eBay out, he may profit from reusing his existing feedback profile. But the current business model of eBay of course excludes that possibility. Technically, it need not be a problem to guarantee the authenticity of portable reputation profiles, through a mechanism similar to that for authentication. Economically, however, the value of keeping those profiles as proprietary content is considerable-and in theory, portable reputation profiles could mean the end of eBay, as any successful client would be able to take his feedback and 'move' to an auction site where transaction costs are lower.

The ship of dispute prevention and dispute resolution is still floating, it seems. From a physical context in which people live together and build social networks, there will be an ongoing change towards virtual networks and on-line communities, in which dispute prevention and dispute resolution have to be supported in different manners. Remodelling social relations in such a manner that people can do business and virtually 'live' together, and thus to solve disputes if they arise, demands a constructive and creative approach towards future applications of technologies. The scenario sketched above is not such a challenge on a technical level-however, much more so on an organizational, economic and legal level. Reusing reputation profiles demands establishing standards for the information contained in them, establishing ways of comparing them, and using them across different domains, and providing sufficient applications to make it worthwhile reusing them.

How difficult is it to imagine that the scenario sketched above will become reality? Not so hard, actually. Microsoft introduced its passport technology years 
ago to provide authentication across different web services. eBay recently bought the VoIP service Skype in order to let its users communicate with each other. Google and Sun have announced collaboration in marketing Open Office. Google already has insight into individual's searching habits and e-mail. On-line word processing lets Google know even more about individual's writings. Potential collaboration between companies such as eBay and Google may create sufficient momentum to pull off the ground something like the portable reputation profiles explained above. If this happens, we had better be prepared for it: we have to know how to use identities and reputation in a useful manner, and how to protect them at the same time. By evaluating their potential consequences, we can anticipate on legal regulation, policies and technical instruments to provide sufficient safeguards for the actual deployment of reputation recycling. In the next section, we discuss how to assess a process of virtualization in dispute resolution.

\section{Assessing virtualization}

In order to be able to assess a scenario like the one in the previous section, we have to establish assessment criteria. Such criteria are always provisional, because they regard phenomena that are not realized as yet. The presence of properly working technological solutions is one of the preconditions for successful applications of ICT. That much anyone could figure out. However, the fact that technology is often a minor factor in successful ICT applications is not clear to many people. Although this seems to be almost a 'truism', still many over-ambitious, improperly implemented ICT solutions can be found. Ignoring the political, social, organizational and psychological factors of ICT does not do justice to what can make ICT into a useful instrument. It is important to stress that, eventually, the use of ICT determines its merits. In regard to the four areas of virtualization, what does this observation mean? What challenges exist in those areas?

The use of ICT for administrative purposes requires a substantial degree of precision and discipline. The models according to which relevant data are stored and exchanged do often not allow for many mistakes-at least, if those mistakes are made, applications will no longer function properly. Whereas paper documents can always be exchanged, and often be properly understood by those receiving them, the same is not valid for electronic documents or data streams, because the information contained in those has to be interpreted and presented by a computer system. If there are mistakes in data models, and the use of ICT becomes frustrating, for instance, because a database application does not allow for the inclusion of a second telephone number, users might be tempted to use different means, or start their own database. If this is the case for something as simple as an address database, how much trouble will an electronic case file give? The most illuminating example of the restrictions imposed by ICT can be read in Reiling's article in this special issue: 'Your Honor, you cannot impose that sanction, Compas [the administrative system for the Dutch judiciary(LM)] cannot process it!'.

In assessing virtualization, we come across the problem that we explained in the introduction: if nothing remains the same in the process of virtualization, we probably cannot use effectively a fixed set of detailed criteria to assess the change from an old into a new situation. Quality assessment frameworks that are used in, for instance, administration of justice may not be relevant to alternative forms of dispute resolution. In the same way, quality assessment frameworks relevant to mediation may not be as relevant to on-line mediation. Still, more fundamental 
frameworks may retain part of their relevance in the process of evaluation. Such a more fundamental frameworks can be based on legitimacy. In Mommers, ${ }^{15}$ a legitimacy framework is proposed, comprising of both structural and substantive criteria. Structural criteria provide preconditions for the layout of institutions and procedures, and substantive criteria regard the nature or content of solutions for disputes. Structural criteria are independence, impartiality, expertise, and accuracy; substantive criteria are rationality, legality, reciprocity and consent. These criteria can be used to assess different virtualization scenarios for dispute resolution. For instance, on the structural side, the fact that eBay provides its own dispute resolution methods could be criticized for its lack of independencealthough eBay is not a party in the buying contract between a seller and a buyer, eBay is definitely a party in the success of eBay's auctions, which depends largely on the number of individual deals closed under its umbrella. On the substantive side, eBay's feedback system could be praised for its conformance to reciprocity: in principle, doing the wrong thing (not delivering the right object, not paying) will put you in a position where this has immediate consequences for your own business, whereas doing the right thing will provide you with positive feedback that boosts your business.

The criteria are important, not only because they support assessing virtualization scenario, but also because they can help designing virtualization scenarios. For instance, what solutions can be proposed for retaining the independence of on-line dispute resolution connected to large e-commerce web-sites? The independence criterion could be implemented by outsourcing dispute resolution to a third party. In the case of eBay's feedback system, which functions mainly as a dispute prevention scheme, outsourcing is not realistic, because the feedback system itself is the backbone of eBay's success. Still, eBay could make visible the dependencies within its feedback system, its own company structure, and its alliances with third parties, in order to make its dispute prevention as transparent as possible. A different example of using legitimacy criteria to design virtualization scenarios, is taking the reciprocity criterion as a starting point. The reciprocity criterion can support the redesign of on-line virtual gatherings into on-line 'communities'. This is necessary because the physical and social distance between individual participants tends to be considerable: participants in on-line forums, for instance, rather quickly get into arguments with each other, in an environment where 'normal' norms of politeness do not apply.

\section{Conclusion}

Virtualization of dispute resolution comprises not only the use of ICT in traditional dispute resolution, but also ways to deal with new types of conflict, arising from the use of ICT (e.g. auctions on the internet). New types of conflict ask for new ways of settling them. The rise of e-commerce on the internet has created a vast number of conflicts, and new ways to tackle them. This is one of the main areas in which on-line dispute resolution has made its appearance-one of the forms virtualization of dispute resolution takes. However, the concept of 'virtualization of dispute resolution' can be stretched to its limits by anticipating scenarios in which dispute resolution is replaced by dispute prevention. Community building on the internet is one of the most important strategies to encourage this development. If principles such as 'do ut des' can be implemented effectively, the chances increase that a true community will develop, with 
mechanisms such as social control redesigned to fit a new, virtual context. A further evaluation of the implications of recycling reputation would not only involve the legitimacy criteria mentioned, but also legal implications of virtualization scenarios. The assessment of such a far-reaching virtualization scenario is hampered by the substantial changes that can take place: the potential change from dispute resolution to dispute prevention is hard to judge from a single assessment framework. Still, the impact virtualization can have deserves sufficient attention in order to maintain legitimacy of dispute resolution.

\section{Acknowledgements}

I thank Aernout Schmidt for his valuable criticisms to an earlier version of this article, which helped me to articulate my ideas in a (hopefully) clearer fashion. Of course, all remaining obscurities, inclarities, and inaccuracies are entirely my own responsibility.

\section{Notes}

1 Wittgenstein, L. (1953) Philosophical Investigations, Oxford, UK, Blackwell, translated from Philosophische Untersuchungen by G.E.M. Anscombe.

2 Susskind, R. (1996) The Future of Law: Facing the Challenges of Information Technology, Oxford, Clarendon Press.

3 Susskind, R. (2000) Transforming the Law, Essays on Technology, Justice and the Legal Marketplace, Oxford, Oxford University Press.

4 Staiksterk.nl: http://www.staiksterk.nl

5 Lessig, L. (1999) Code and Other Laws of Cyberspace, New York, Basic Books.

6 Katsh, E. \& Rifkin, J. (2001) Online Dispute Resolution: Resolving Conflicts in Cyberspace, San Francisco, CA, Jossey-Bass.

7 Mommers, L. (to appear) Promoting legitimacy: feedback in dispute resolution. in Artificial Intelligence and Law, Springer Netherlands.

8 Euro Label: http://www.euro-label.com

9 Tweakers.net shop survey: http://www.tweakers.net/shopsurvey

10 Shopping.com: http://www.shopping.com

11 Carey, M. (2003) P2P Reputation Systems: Can peer-to-peer (P2P) reputation systems work? Available online at: http://www.markcarey.com/web-dawn/archives/p2p-reputation-systems. html

12 Dingledine, R., Mathewson, N. \& Syverson, P. (2003) Reputation in P2P anonymity systems. in Proceedings of Workshop on economics of $p 2 p$ systems.

13 Mommers (to appear) op. cit.

14 Ellickson, R.C. (1991) Order without Law: How Neighbors Settle Disputes, Cambridge, MA, Harvard University Press.

15 Mommers (to appear) op. cit. 